\title{
Measurement of Streaming Potential in Downhole Application: An Insight for Enhanced Oil Recovery Monitoring
}

\author{
Tengku Amran Tengku Mohd ${ }^{1,2}$, Mohd Zaidi Jaafar ${ }^{1, a}$, Azad Anugerah Ali Rasol $^{1}$, Mohd Fauzi Hamid ${ }^{1}$ \\ ${ }^{1}$ Faculty of Chemical and Energy Engineering, Universiti Teknologi Malaysia, Skudai, MALAYSIA \\ ${ }^{2}$ Faculty of Chemical Engineering, Universiti Teknologi MARA, Shah Alam, MALAYSIA
}

\begin{abstract}
Downhole monitoring using streaming potential measurement has been developing in order to respond to actual reservoir condition. Most studies have emphasized on monitoring water flooding at various reservoir condition and improving the approaches of measurement. Enhanced Oil Recovery (EOR) could significantly improve oil recovery and the efficiency of the process should be well-monitored. Alkaline-surfactant-polymer (ASP) flooding is the most promising chemical EOR method due to its synergy of alkaline, surfactant and polymer, which could enhance the extraction of residual oil. However, limited studies have been focused on the application of streaming potential in EOR processes, particularly ASP. Thus, this paper aims to review the streaming potential measurement in downhole monitoring with an insight for EOR application and propose the potential measurement in monitoring ASP flooding. It is important for a preliminary study to investigate the synergy in ASP and the effects on oil recovery. The behaviour of streaming potential should be investigated when the environment of porous media changes with respect to ASP flooding. Numerical model can be generated from the experimental data to forecast the measured streaming potential signal during production associated with ASP flooding. Based on the streaming potential behaviour on foam assisted water alternate gas (FAWAG) and water alternate gas (WAG) processes, it is expected that the streaming potential could change significantly when ASP flooding alters the environment and surface properties of porous media. The findings could provide new prospect and knowledge in the relationship between streaming potential and ASP mechanisms, which could be a potential approach in monitoring the efficiency of the process.
\end{abstract}

\section{Introduction}

Real-time permanent monitoring and control is important in maximizing the hydrocarbon production from oil and gas wells. Permanent downhole sensors have been previously investigated to optimize reservoir management $[1,2,3]$. According to Brinsden (2005), an effective development and optimization of oil and gas reservoirs requires long-term reservoir monitoring and control, which is important in both new and mature fields [4]. Therefore, many downhole monitoring techniques have been proposed and developed in order to resolve any difficulties, cost and maintenance associated with the installation of the tools.

Streaming potential measurement applying electrodes permanently installed downhole has been a promising reservoir-monitoring technology [5,6]. Jaafar et al. (2009) have measured the streaming potential coupling coefficient in sandstones saturated with higher brine salinity and reported the values of streaming potential coupling coefficient changed with respect to rock texture or mineralogy, injected and formation brine salinity [7]. Jackson et al. (2011) found that the streaming potential at the well changed when the encroached water on a production well was several tens to hundreds of meters away [8]. The contrast with most other downhole monitoring techniques provides great advantages in monitoring the efficiency of secondary or tertiary recovery processes. Jaafar et al. (2013) found the point of zero charge (pzc) of two types of core samples (sandstone and carbonate), where the voltage difference was measured at different $\mathrm{pH}$ of solution, but there were no further study on the effect of the degree of alkalinity to the streaming potential [9]. In 2014, Walker et al. applied new pressure transient approach as a faster approach than the conventional measurement methods, where the measured streaming potential coupling coefficients and zeta potential were aligned with the findings by Vinogradov et al. (2010) at high salinity [10,11]. Results obtained by Esmaeili et al. (2016) agreed with the published experimental data, and much lower scattering in the data points was achieved for different saline injecting water [12]. Streaming potential changes accordingly with the wetting state of the rock surface. When the wettability of rock partially changes to the oilwet, the overall zeta potential and coupling coefficient approach to their values of completely oil-wet sand particles [13]. Surfactant has the ability to reduce interfacial tension, as well as changing the wetting state

\footnotetext{
a Corresponding author: mzaidi@utm.my
} 
of the rock surface, which require further studies on the influences to the streaming potential.

It is evident that original rock surface properties and its modification during the EOR process determine the efficiency of oil recovery from reservoirs. The minerals and surface properties of the reservoir are very sensitive to any alteration of the fluids properties. ASP changes the environment in porous media, including IFT reduction, wettability alteration, ionic adsorption at the interface and degree of alkalinity [14], which could improve sweep efficiency. ASP provides synergy of alkaline, surfactant and polymer [15]. ASP mechanisms should be well understood, since they have significant effects on the behaviour of streaming potential. Zeta potential is one of the critical parameters to characterize the surface properties, where its average measurement of reservoir rock could be potentially estimated using streaming potential measurement as a new promising tool. [16]. There were no further studies from past researchers on how streaming potential behaves and its significant uncertainties when ASP changes the properties of porous media. Thus, the purpose of this paper is to review the streaming potential measurement in downhole monitoring with an insight on EOR application and propose the potential of streaming potential application in ASP flooding. This could provide new prospect and knowledge in the relationship between streaming potential and ASP mechanisms.

\section{Streaming Potential}

Electrokinetic is a group of physicochemical phenomena, which involves the transport of charge, action of charged particle, effect of applied electrical potential and fluid transport in porous media to achieve a desired fluid flow or migration. The phenomena included are streaming potential, electroosmosis, electrophoresis and reduction potential. Streaming potential is widely used in detection of contamination in the subsurface water table and currently study extended to enhanced oil recovery application. Streaming potential is defined as a result of electric current generated whenever an electrolyte move with respect to stationary solid that is in contact with in a case water flow through earth and rock [17]. This was first observed in capillary tubes by Quincke in 1859 [18], and a theoretical model for the effect in capillaries was later developed by Helmholtz in 1879 [19]. That model is still being applied currently and proved to be valid for flow though porous media.

The mechanism of streaming potential is fluid flow in porous media cause the electric conduction current which flow in reverse direction through both liquids and solid matrix [20]. The conduction current acts to cancel the convection current in a steady state. Solid matrix that electrically conductive in any degree will reduce the magnitude of the streaming potential. When a fluid flows with respect to a solid that it is in contact with, the solid surfaces are induced to be electrically charged. The fluid carries with it charged particles that are attracted to the charged surface of the solid, forming a diffuse layer containing excess of countercharge [4]. Extra double layers could be produced at fluid/fluid interfaces with the presence of more than one phase [21].

\subsection{Streaming Potential Measurement}

The electrical double layer formed at solid/fluid interface is the origin of streaming potentials in porous media [21]. If an external pressure gradient induces the fluid to flow, the flow will carry some excess charge within the diffuse layer, which could increase the streaming current. Density divergence of the streaming current produces an electrical potential, known as streaming potential [11]. The coupling coefficient (C) provides the relationship between the fluid $(\nabla \mathrm{P})$ and electrical $(\nabla \mathrm{V})$ potential gradients at zero total current density (j), as expressed in Eq. 1 [22].

$$
C=\left.\frac{\partial V}{\partial P}\right|_{j=0}
$$

Thus, the magnitude of the streaming potential could be predicted if the fluid potential is known. The coupling coefficient is a function of the electrical conductivity of the brine $\left(\sigma_{\mathrm{w}}\right)$ and brine-saturated rock $\left(\sigma_{\mathrm{rw}}\right)$, permittivity $\left(\varepsilon_{\mathrm{w}}\right)$ and viscosity $\left(\mu_{\mathrm{w}}\right)$ of the brine, and the zeta potential $(\zeta)$, which is the microscopic electrical potential subjected to the excess charge in the double layer. It can be shown as in Eq. 2 [21].

$$
C=\frac{\varepsilon_{w} \zeta}{\mu_{w} \sigma_{r w} F}
$$

$\mathrm{F}$ is the formation factor $\left(\sigma_{\mathrm{w}} / \sigma_{\mathrm{rw}}\right)$ measured when surface conductivity is negligible (associated with very saline brine).

\subsection{Numerical Simulation of Streaming Potential}

Numerical simulation of streaming potentials is important in understanding the phenomenon and for self-potential anomalies interpretation. Many simple models involving charged bodies of various shapes have been constructed, but not realistic since they did not consider the nature of all sources that generated the potentials. As mentioned previously, streaming potentials result from electric currents created by the flow of a liquid with respect to a solid. The current flow, defined by Ohm's law and the fluid flow, defined by Darcy's law, can be correlated by the theory of coupled flows. With reference to the earlier work of Marshall and Madden (1959) [23], Nourbehecht (1963) has produced the first model applying this approach, where solutions were formulated in terms of a total- or pseudo-potential [24]. However, the pseudopotential approach misrepresented the actual mechanisms that generate streaming potentials, and only applicable to hydraulically driven fluid flow. Its application to more complex geometries can be difficult

A new approach for modelling streaming potentials was developed by Sill (1983), who also applied the coupled flow theory and formulated explicit expressions for the involved current sources [22]. His approach is 
straight-forward even when application on complex geometries, and can be applied as well to nonhydraulically driven fluid flow such as that generated by temperature gradients. Sill's method is more analogous to the actual physical process involved and forms the basis for most modern modelling of the streaming potential phenomenon.

\section{Electrical Double Layer (EDL) and Zeta Potential}

Electrical double layers (EDL) is very important factor in electrokinetic phenomena. A fundamental of understanding the physical properties of EDL is zeta potential which can be defined as electrical potential in electrolyte. A simple model describing the potential distribution in EDL is illustrated in Fig. 1. The slipping (shear) plane is defined as the point which the liquids begin to flow in a small distance from the solid surface. By definition, zeta potential is the electrical potential as this shear plane. Zeta potential is directly proportional to the surface charge that developed on the solid surface when in it is in contact with electrolyte [25]. However if the solid material already possesses a surface charge due to an imbalanced crystal structure, the two main chemical processes that act to develop a surface charge are the adsorption of ions and the hydrolysis of surface hydroxyl groups. Both of these processes typically occur simultaneously and depending on the chemical compositions of both the electrolyte and the solid. The chemistry at the interface can be treated by general chemical equilibrium equations and the equilibrium constants for many materials can be found in chemistry texts. The $\mathrm{pH}$ value of the electrolyte influences the surface charge and hence zeta potential in a solid and liquids chemical composition. The $\mathrm{pH}$ has a large effect on the hydrolysis of the surface hydroxyl group and lesser in ion adsorption [26]. By chemical equilibrium equation, the surface charge density is decreased with increasing $\mathrm{pH}$. As a result, the zeta potential also decrease with increasing $\mathrm{pH}$.

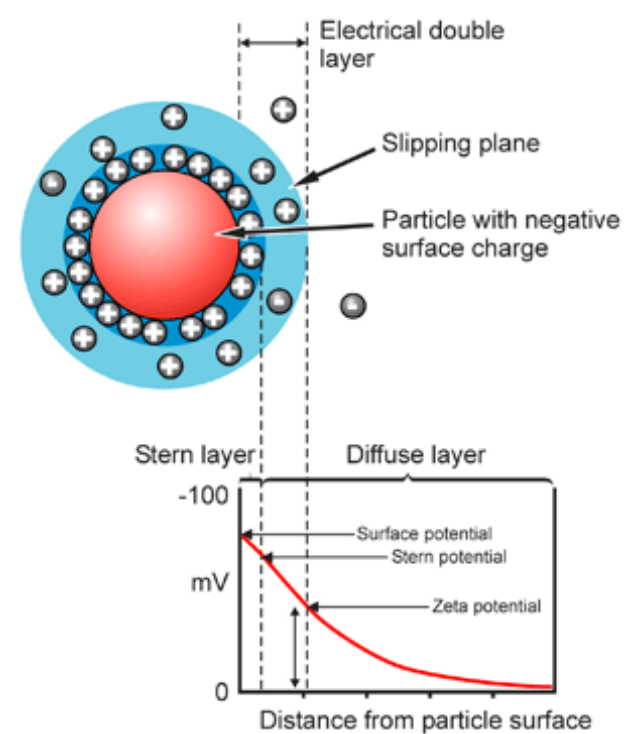

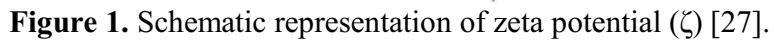

\section{Enhanced Oil Recovery}

Enhanced Oil Recovery (EOR) or tertiary recovery is has been applied to achieve higher oil recovery from a reservoir that could not be produced by primary and secondary recoveries [28]. According to Collins (1977), EOR is the incremental production of oil with the introduction of artificial energy into the reservoir and can be divided into three major categories that are thermal EOR, chemical EOR and miscible EOR [29]. The performance of EOR processes is assessed based on the reservoir rocks characteristics and properties of displacing and displaced fluids. The reservoir rocks characteristics include rock porosity, wettability, as well as oil and water permeability of the porous media while the properties of displacing and displaced fluids are such as flow velocities and interfacial tension at fluid interface [30]. Hill et al. (2010) suggested modification of the reservoir matrix and fluid properties such as the viscosities of liquid phases, interfacial tension between two immiscible phases, rock wettability, and the capillary forces within the matrix [31]. This could increase the oil recovery, decrease water cut and reduce the residual oil saturation. ASP flooding is one of the promising chemical EOR methods, which provides the synergy of alkaline, surfactant and polymer in enhancing oil recovery.

\subsection{Alkaline-Surfactant-Polymer Flooding}

ASP flooding is a chemical EOR process which involves the injection of surfactant, alkaline and polymer into an oil reservoir targeted to produce the remaining residual oil, which could not be recovered by conventional water flood [32]. In addition, most of the oil fields have been under water flooding, which favour the implementation of chemical EOR method. Therefore, the facilities required to add chemicals in the injection water could be reduced [15]. ASP flooding is subjected to several processes in enhancing oil recovery, including interfacial tension (IFT) reduction between trapped oil phase and ASP slug [32,33], improving mobility control and sweep efficiency [34] as well as wettability alteration by surfactant to more favourable state [35].

ASP flooding ensures more efficient displacement through IFT reduction between oil and water with the addition of surfactant, while addition of polymer could improve the oil and water mobility [36]. Addition of alkali could reduce adsorption of the surfactant onto the rock surface besides controlling the salinity for minimum IFT and rock wettability alteration [36]. Thus, oil recovery could be significantly improved by ASP flooding [37].

\subsubsection{Mechanisms of Polymer Flooding}

Polymer flooding results in reducing the mobility with addition of polymer to the water during water flooding. Viscosity of the aqueous phase is increased by the polymer and water permeability is reduced due to mechanical entrapment, resulting in more favorable mobility ratio. With a more viscous phase, a more stable 
displacement can be achieved, which ensures the easier movement of the oil through the reservoir and into the producing well, improving the sweep efficiency $[38,39]$. It has been reported that a successful polymer application can achieve an incremental recovery factor of higher than $5 \%$ OOIP (original oil in place) [40,41]. Due to polymer viscoelastic properties, a larger pull force is exerted on oil droplets or oil films, which reduces residual oil saturation [42].

\subsubsection{Mechanisms of Surfactant Flooding}

The surfactant flooding aims to produce the residual oil trapped by the capillary action, which could not be recovered by a conventional water flooding. Its key mechanism is the reduction in the IFT between oil and water, which aid in mobilizing the residual oil. Since the higher the capillary number, the lower residual oil saturation [43], the three ways to increase the capillary number are by increasing the velocity of injection fluid, enhancing the viscosity of displacing fluid as well as ensuring the IFT reduction. IFT reduction is the most preferable method due to its practicality, where IFT reduction between oil and a surfactant solution can be achieved in the range of $20-30$ to $10^{-3} \mathrm{mN} / \mathrm{m}$. Instead, the injection fluid velocity is limited by pump capacity or formation injectivity leading to formation fracture, while increasing injection fluid viscosity using too high polymer concentration is associated with solubility issue [15]. Crude oil contains organic acid and salts, alcohols and other natural surface-active agents. When the crude oil is in contact with brine or water, an adsorbed film is formed by the accumulation of natural surfactants at the interface, which reduces the IFT of the crude oil/water interface [44]

\subsubsection{Mechanisms of Alkaline Flooding}

The injected alkaline or caustic solutions will react with the natural acids (naphthenic acids) contain in the crude oils to form in-situ surfactants (sodium naphthenate). The produced surfactants act similarly with the synthetic surfactants injected into the reservoir to ensure the IFT reduction between oil/water [44]. This generated surfactant is referred as soap in order to distinguish it from the synthetic surfactant. The reaction equation is as follows [15]:

$$
\mathrm{HA}+\mathrm{OH}^{-} \rightarrow \mathrm{A}^{-}+\mathrm{H}_{2} \mathrm{O}
$$

where HA is known as pseudo-acid component and $\mathrm{A}^{-}$is the soap component. In ASP process, alkali has significant role in reducing the amount of surfactant adsorbed on the grain surfaces through the formation and sequestering of divalent ions. Therefore, less surfactant injection is required, which ensures the surfactant to work more efficiently. Total Acid Number (TAN) of the oil affects how the alkali works in ASP flooding. Nelson et al. (1984) found the reduction of oil-water IFT during alkaline injection for oil with high TAN due to the combination effects of the generated soap with the injected surfactant [45]. However, alkali can still significantly reduce surfactant adsorption for oil with low TAN [46]. Liu et al.
(2008) has proved that soap-to-surfactant ratio is important, which has significant contribution in order to understand the ASP process [47]. Besides, formation wettability can be altered with the presence of alkali to become more oil-wet or water-wet. Other mechanisms involved are such as emulsification, oil entrainment and bubble entrapment [48].

\subsubsection{Mechanisms and Synergy in ASP}

An emulsion is formed from the alkali-surfactant mixture with the oil, where a displacement takes place using a polymer drive to be recovered from the reservoir. Addition of surfactant in ASP flooding ensures the IFT reduction between oil and water, where the mobility ratio is further improved by the addition of polymer, resulting in improving displacement [36]. Addition of alkali to the water could minimize the amount of adsorbed surfactant onto the rock surface, which could ensure minimum IFT and rock wettability alteration [36]. An important mechanism in ASP is the synergy provided between synthetic surfactant and the generated soap. Generally, the synthetic surfactant has high optimum salinity, whereas the soap has unrealistically low optimum salinity. However, an increased range of salinity in which IFT reaches its low values could be achieved when they are functioning together [45]. Synergistic IFT reduction is produced by the surfactant and alkali while polymer improves sweep efficiency by emulsions [14]. The summary of mechanisms and synergies in ASP is shown as follows [15]:

1. Amount of adsorbed surfactant is reduced by alkaline injection.

2. In-situ soap is generated from the reaction of alkali and crude oil, which functioning together with synthetic surfactant to provide an increase of salinity range in which IFT reaches its low values.

3. Improvement of sweep efficiency by the emulsions, since IFT is reduced by soap and surfactant while emulsions are stabilized by high viscous polymer to retard coalescence.

4. Surfactant adsorption is reduced by addition of polymer, or vice versa, as there is an adsorption competition between polymer and surfactant [49].

5. Addition of polymer improves the sweep efficiency of alkaline and surfactants.

6. The decrease of liquid production was not only due to increase of the displacing fluid viscosity, but also related to emulsification and scaling after injection of ASP slug [50].

\section{Measurement of Streaming Potential in Monitoring EOR}

Measurement of streaming potential in downhole application using electrodes has recently been introduced, but there is still a significant degree of uncertainty in measuring and interpreting the streaming potential results. Two field tests were successfully carried out by Chen et al. (2006) for the first time. They have measured 
the streaming potential generated from pressure transients by electrodes located in the borehole [51] and found two responses of the recorded streaming potential on the pressure changes. These resulted from water flooding into high permeability fracture and rock matrix. Therefore, this indicated that streaming potential measurement has high potential application in petroleum industry for reservoir monitoring as well as reservoir characterization. Streaming potential measurement has been a promising reservoir monitoring technique, but many studies have been focused on the water flooding brine-saturated porous media and the recent analysis of streaming potential at varying brine salinity $[7,12,13]$. Limited studies have been conducted to measure streaming potential in monitoring EOR processes, such as water alternate gas (WAG) and foam assisted water alternate gas (FAWAG) by Anuar et al. and Omar et al. $[52,53,54,55]$.

Basically WAG is a process where intermittent slugs of gas and water are injected into the reservoir. Threephase (gas, oil and water) flow is better than two-phase flow in recovering residual oil in the pore space [56]. Water can control the mobility for more stable displacement which could improve the gas injection sweep efficiency. WAG could control gas fingering thus enhancing the vertical sweep efficiency. While FAWAG could improve the sweep efficiency during gas injection by reducing the Gas Oil Ratio (GOR) and maximizing hydrocarbon production rate in the production tubing [57]. In addition, foam improves gas mobility control by delaying the early gas breakthroughs.

Omar et al. (2013) has measured the streaming potential resulted from the flowing fluid in FAWAG process to be correlated with the foam stability [53]. The principle is similar with the water flooding to monitor the process, but it provides indirect measurement of foam stability in order to monitor the efficiency of the EOR process. Since foamability and stability are the key factors for enhancing the recovery [58], measuring streaming potential could aid in monitoring the foam stability from the surface. Using the same principle from Kostoglou et al. (2010) [59], their research was based on theory that the FAWAG process flowing in the porous medium could produce an electric current, where electrokinetic signal pattern varied with the changes of foam stability [53]. In 2014, Omar et al. found that the increase in surfactant concentration, sodium dodecyl sulphate (SDS) has decreased the voltage (electrokinetic potential) and decreased as shown in Fig. 2 [54]. Thus, electrokinetic methods have been applied to understand the conductive properties of foam as well as for investigation of the initial expansion and subsequent stability of various foams. Fig. 3 shows the relationship between electrokinectic signal and foam rupture time during the FAWAG process in the porous media at various SDS concentration. It was found that the voltage increased when increase in foam stability, thus electrokinectic potential has significant effects in monitoring foam stability during FAWAG process.

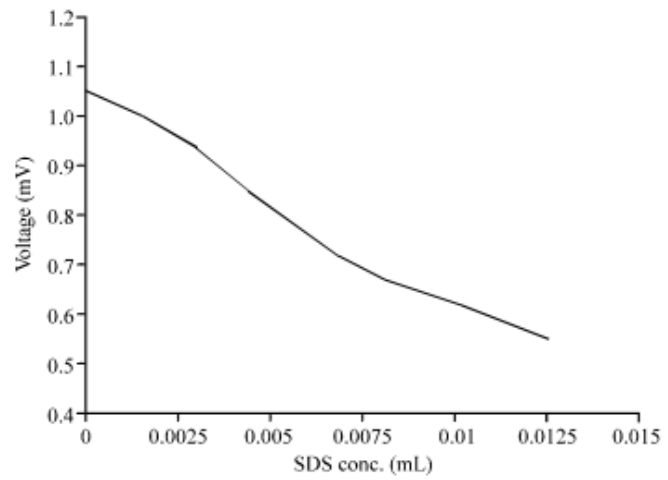

Figure 2. Relationship between voltage and SDS concentration [54].

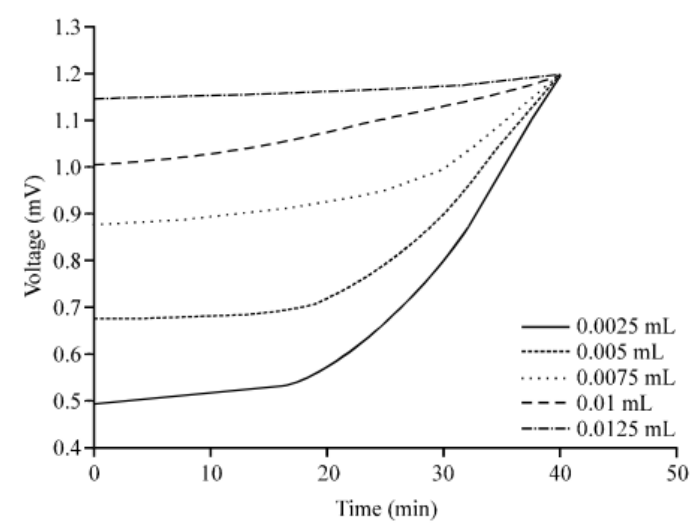

Figure 3. Relationship between electrokinetic signal and foam stability with time [54].

Anuar et al. (2013) proposed the application of streaming potential in monitoring WAG process as it could provide real-time monitoring [52], overcoming the longer process taken by tracer system [60]. The research was conducted based on the principle that water is conductive, while gas is non-polar and resistive, thus different effects could be observed on the voltage measurement (streaming potential). Fig. 4 illustrates the streaming potential profile during WAG process, indicating high streaming potential signals when water is flowing, while low signals when the present of gas. Streaming potential signals at different electrodes are shown in Fig. 5, where similar profile was observed but different responses between each other due to different location of electrodes. It can be concluded that streaming potential has significant effects on WAG process, which could effectively monitor the progress of water and gas in enhancing oil recovery [55].

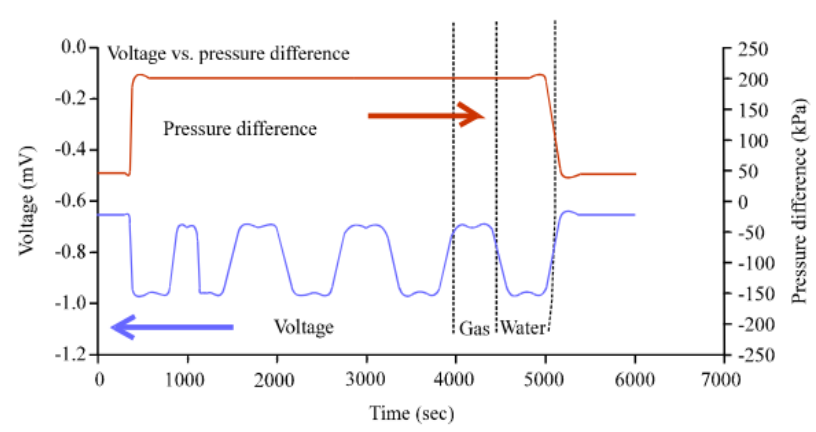

Figure 4. Streaming potential profile during WAG process [55]. 


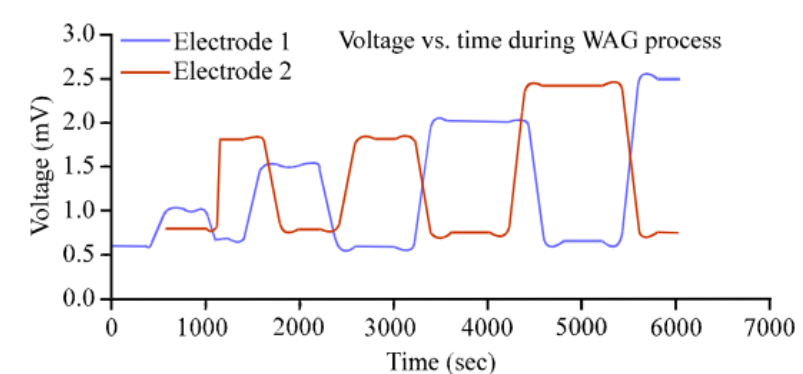

Figure 5. Streaming potential signals at different electrodes [55].

Many studies have been conducted to measure streaming potential related to groundwater movement and hydrocarbon production. However, there is a significant degree of uncertainty in the behaviour of streaming potential when the porous media changes, particularly with respect to alkalinity, ionic adsorption onto the rock surface and the interfacial tension (IFT) between the fluids residing in the pore space during ASP flooding. From the mechanisms of alkaline, surfactant and polymer flooding as well as the synergy in ASP, the interaction between the chemicals, the reservoir fluids and the rock surface could enhance the oil recovery [32]. The original rock surface properties and its modification during the EOR process will affect the efficiency of oil recovery from reservoirs. The minerals and surface properties of the reservoir are very sensitive to any alteration of the fluids properties.

Thus, there is a need for future studies to investigate streaming potential in monitoring ASP flooding, since ASP could provide the synergy, resulting in further enhancing oil recovery. Understanding the mechanisms involved in ASP flooding is vital in predicting the behaviour of streaming potential with respect to the interactions. This EOR process should be monitored effectively to ensure that the process is at optimum condition. In addition, the experimental data acquired can be applied in a numerical model to predict the streaming potential signal that would be measured during production associated with ASP flooding. From the review of the streaming potential theory and concept, as well as the ASP and its individual mechanisms, streaming potential measurement is believed to have a great potential in monitoring ASP flooding.

\section{Conclusion}

Approaches of streaming potential measurement in water flooding application have been improved. There is a need for further studies in EOR monitoring, since streaming potential behaviour has changed significantly during FAWAG and WAG processes. The synergy of alkaline, surfactant and polymer has revealed the ASP flooding to be an attractive and the most promising chemical EOR method. Thus, the process should be monitored effectively to ensure optimum recovery of residual oil. There are significant uncertainties in the streaming potential behaviour when the porous media changes, particularly with respect to alkalinity, ionic adsorption onto the rock surface and the interfacial tension (IFT) between the fluids residing in the pore space, potentially produced by ASP flooding. It is critical to understand the streaming potential behaviour and its relation with ASP mechanisms for efficient monitoring of ASP flooding. The streaming potential signals measured during production could be potentially predicted using numerical modelling. Application and measurement of streaming potential to monitor ASP flooding in the real field could benefit the oil industry in term of making the EOR process more efficient and economic.

\section{Acknowledgment}

The authors would like to express appreciation to the Faculty of Chemical and Energy Engineering, UTM Skudai for the facilities provided and constant encouragement. This work was financially supported by Fundamental Research Grant Scheme (FRGS) Vote: 4F561.

\section{References}

1. Chalaturnyk, R. and Moffatt, T. (1995). Permanent instrumentation for production optimization and reservoir management. Paper SPE 30274-MS proceedings of the SPE International Heavy Oil Symposium, Calgary, Alberta, 19-21 June.

2. Wu, Z., Alpak, F. O. and Torres-Verdin, C. (2003). A quantitative study to assess the value of pressure data acquired with in-situ permanent sensors in complex 3D reservoir models subject to two-phase fluid flow. Paper SPE 84375-MS proceedings of the SPE Annual Technical Conference and Exhibition, Denver, Colorado, 5-8 October.

3. Silva, M. I. and Kato, E. T. (2004). Reservoir management optimization using permanent downhole gauge data. Paper SPE 90973-MS proceedings of the SPE Annual Technical Conference and Exhibition, Houston, Texas, 26-29 September.

4. Brinsden, M. S. (2005). A New Wireless Solution to Real Time Reservoir Surveillance. Presented at the SPE Middle East Oil and Gas Show and Conference, Manama, Bahrain, 12-15 March. SPE-93512-MS.

5. Jackson, M. D., Saunders, J. H., and AddiegoGuevara, E. A. (2005). Development and Application of New Downhole Technology to Detect Water Encroachment toward Intelligent Wells. Paper SPE 97063 presented at the SPE Annual Technical Conference and Exhibition, Dallas, 9-12 October.

6. Saunders, J. H., Jackson, M. D. and Pain, C. C. (2008). Fluid flow monitoring in oil fields using downhole measurements of electrokinetic potential, Geophysics, Vol. 73(5).

7. Jaafar, M. Z., Vinogradov, J., and Jackson, M. D. (2009). Measurement of streaming potential coupling coefficient in sandstones saturated with high salinity $\mathrm{NaCl}$ brine. Geophysical Research Letters 36: L21306.

8. Jackson, M. D., Vinogradov, J., Saunders, J. H. and Jaafar, M. Z. (2011). Laboratory Measurements and 
Numerical Modeling of Streaming Potential for Downhole Monitoring in Intelligent Wells, SPE 120460, September 2011 SPE Journal.

9. Jaafar, M., Nasir, A. and Hamid, M. (2013). Point of Zero Charge for Sandstone and Carbonate Rocks by Streaming Potential. International Journal of Petroleum \& Geoscience Engineering (IJPGE), 1(2): 82-90.

10. Walker, E., Glover, P. and Ruel, J. (2014). A transient method for measuring the DC streaming potential coefficient of porous and fractured rocks. Journal of Geophysical Research: Solid Earth, 119(2): 957-970.

11. Vinogradov, J., Jaafar, M. and Jackson, M. (2010). Measurement of streaming potential coupling coefficient in sandstones saturated with natural and artificial brines at high salinity. Journal of Geophysical Research: Solid Earth (1978-2012), 115(B12).

12. Esmaeili, S., Rahbar, M., Pahlavanzadeh, H. and Ayatollahi, S. (2016). Investigation of streaming potential coupling coefficients and zeta potential at low and high salinity conditions: Experimental and modeling approaches. Journal of Petroleum Science and Engineering, 145, 137-147.

13. Sadeqi-Moqadam, M., Riahi, S. and Bahramian, A. (2016). Monitoring wettability alteration of porous media by streaming potential measurements: Experimental and modeling investigation. Colloids and Surfaces A: Physicochemical and Engineering Aspects. Elsevier B.V.

14. Sheng J. J. (2011). Modern chemical enhanced oil recovery: theory and practice. Elsevier; 2011.

15. Sheng, J. J. (2013). SPE 165358, A Comprehensive Review of Alkaline-Surfactant-Polymer (ASP) Flooding, Paper SPE 165358 proceedings of the SPE Western Regional \& AAPG Pacific Section Meeting, Monterey, California, USA, 19-25 April 2013.

16. Chen, L., Zhang, G., Wang, L., Wu, W. and Ge, J. (2014). Zeta potential of limestone in a large range of salinity. Colloids and Surfaces A: Physicochemical and Engineering Aspects, 450: 1-8.

17. Wurmstich, B., Morgan, E. D., Texas, A., Merkler, G., Lytton, R. L., Texas, A., and G, E. (1994). Engineering and Groundwater 3 : Case Histories II Potentials Due to Seepage : Study of a Dam, 3-5.

18. Quincke, G. (1859). Concerning a new type of electrical current. Annalen der Physics and Chemie (Poggendorff's Annal., Ser. 2) 107, 1-47.

19. Helmholtz, H. (1879). Studien uber electrische grenzschichten. Ann. Phys. Chem. 7(ser.3):337-382.

20. Jackson, M., Gulamali, M., Leinov, E., Saunders, J. and Vinogradov, J. (2012). Spontaneous Potentials in Hydrocarbon Reservoirs During Waterflooding: Application to Water-Front Monitoring. SPE Journal, 17(1), 53-69.

21. Hunter, R. J. (1981). Zeta Potential in Colloid Science, Academic, New York.

22. Sill, W. R. (1983). Self-potential modeling from primary flows, Geophysics, 48, 76-86.
23. Marshall, D. J. and Madden, T. R. (1959). Induced polarization, a study of its causes, Geophysics, 24(4): 790-816.

24. Nourbehecht, B. (1963) Irreversible thermodynamics effect in inhomogeneous media and their applications in certain geoelectric problems, Ph.D. thesis, Mass. Inst. Of Technol., Cambridge.

25. Luong, D. T., and Sprik, R. (2014). Examination of a Theoretical Model of Streaming Potential Coupling Coefficient, 2014.

26. Zhang, W., Yao, J., \& Sun, H. (2015). Electrokinetic coupling in single phase flow in periodically changed capillary with a very small throat size. International Journal of Heat and Mass Transfer, 84, 722-728.

27. Chilingar, G. V. Haroun, M., Shojaei, H. and Shin, S. (2014). Introduction to Electrokinectics, Electrokinetics for Petroleum and Environmental Engineers. Scrivener Publishing.

28. Stosur, G. J., Hite, J. R., Carnahan, N. F., and Miller, K. (2003). The Alphabet Soup of IOR, EOR and AOR: Effective Communication Requires a Definition of Terms. SPE International Improved Oil Recovery Conference in Asia Pacific, Kuala Lumpur, Malaysia, October 20-21, 2003.

29. Collins, A. (1977). Enhanced-Oil-Recovery Water Injections. In SPE-AIME International Symposium on Oilfield and Geothermal Chemistry. La Jolla, California.

30. Zhang, T., Davidson. D., Bryant S. L. and Huh. C. (2010). Nanoparticle-Stabilized Emulsions for Applications in Enhanced Oil Recovery, SPE/DOE Paper 129885, to be presented at SPE Improved Oil Recovery Symp., Tulsa, OK., Apr. 26-28

31. Hill, D. G., Wittle J. K., Fricker, D. J., and Chilingar, G. V. (2010). Moving Goo: Direct Electric Current Oil Recovery (EEOR)-A New Approach to Enhancing Oil Production, Sacramento Petroleum Association, November 17.

32. Austine, J., Van Batenburg, D. W., Southwick, J. G., Zarubinska, M. A., Paramanathan, S., Bouwmeester, R. C. M., Kechut, N. I., Viig, S. O., Haugen, O. B., and Brandvoll, Ø. (2015). Laboratory Evaluation of Inter-Well Partitioning Tracers for the determination of remaining oil saturation after ASP flooding. Paper SPE-174610-MS proceedings of the SPE Enhanced Oil Recovery Conference, Kuala Lumpur, Malaysia, 11-13 August 2015.

33. Flaaten, A. K., Nguyen, Q. P., Pope, G .A and Zhang, J. (2009). A Systematic Laboratory Approach to Low-Cost, High-Performance Chemical Flooding. SPE Reservoir Evaluation \& Engineering. Volume 12, Number 5. October 2009. pp. 713-723. SPE paper 113469-PA.

34. Shen, P., Wang, J., Yuan, S., Zhong, T. and Jia, X. (2009). Study of Enhanced-Oil-Recovery Mechanism of Alkali/Surfactant/Polymer Flooding in Porous Media from Experiments. SPE Journal. Volume 14, Number 2. June 2009. pp. 237- 244. SPE paper 126128-PA.

35. Spinler, E. A. and Baldwin, B. A. (2000). Surfactant Flooding in Enhanced Oil Recovery. In Schramm, L. L. (Ed.) Surfactants Fundamentals and Applications 
in the Petroleum Industry. 1ed. Cambridge, Cambridge University Press.

36. Hirasaki, G. J., Miller, C. A., Puerto, M. (2011). Recent advances in surfactant EOR. Soc Pet Eng J 2011;16:889-907.

37. Stoll, W. M., Al Shureqi, H., Finol, J., Al-Harthy, S. A. A., Oyemade, S. and De Kruijf, A. (2011). Alkaline/surfactant/polymer flood: from the laboratory to the field. SPE Reserv Eval Eng 2011;4(6):704-712.

38. Sorbie, K. S. (1991). Polymer-Improved Oil Recovery, CRC Press, Inc., Boca Raton, Florida.

39. Gao, S., Li, H., Li, H. (1995). Laboratory investigation of combination of alkali/ surfactant/polymer technology for Daqing EOR. SPE Resrv Engg 10:194-197

40. Rai, K., Mccomb, T., Rodriguez, E., Withers, R., Company, C. E. T. (2012). Development of a tool to predict technical Success of polymer flooding applications. Society of Petroleum Engineers, SPE; 2012. SPE 153878.

41. Singhal A. (2011). Preliminary review of IETP projects using polymers. 2011.

42. Wang, D. M., Cheng, J. C., Yang, Q. Y., Gong, W. C., Li, Q., and Chen, F. M. (2000). Viscous-elastic polymer can increase microscale displacement efficiency in cores, paper SPE 63227 presented at the SPE Annual Technical Conference and Exhibition, Dallas, Texas, 1-4 October.

43. Stegemeier, G. L. (1977). Mechanisms of entrapment and mobilization of oil in porous media, In Improved Oil Recovery by Surfactant and Polymer Flooding, (D.O. Shah and R.S. Schechter, eds.), pp. 55-91, Academic Press, New York.

44. Olajire, A. A. (2014). Review of ASP EOR (alkaline surfactant polymer enhanced oil recovery) technology in the petroleum industry: Prospects and challenges. Energy, 77, 963-982.

45. Nelson, R. C., Lawson, J. B., Thigpen, D. R., and Stegemeier, G. L. (1984). Cosurfactant-enhanced alkaline flooding. Paper SPE 12672 presented at the SPE/DOE Fourth Symposium on Enhanced Oil Recovery held in Tulsa, Oklahoma, 15-18 April.

46. Southwick, J. G., van den Pol, E., van Rijn, C. H. T., van Batenburg, D. W., Boersma, D. M., Svec, Y., Mastan, A. A., Shahin, G. T., and Raney, K. (2014). Ammonia as alkali for ASP floods - Comparison to sodium carbonate. In SPE Improved Oil Recovery Symposium, Tulsa, Oklahoma, USA. SPE 169057.

47. Liu, S., Zhang, D. L., Yan, W., Puerto, M., Hirasaki, G. J. and Miller, C. A. (2008). Favorable attributes of alkaline-surfactant-polymer flooding. Soc Pet Eng J 2008;13(1):5-16.

48. Johnson Jr., C. E. (1976). Status of caustic and emulsion methods. JPT (January), 85-92.

49. Wang, J., Han, M., Fuseni, A. B., \& Cao, D. (2015). Surfactant Adsorption in Surfactant-Polymer Flooding for Carbonate Reservoirs. SPE-172700MS: SPE Middle East Oil \& Gas Show and Conference, Manama, Bahrain, 8-11 March 2015.

50. Zhu, Y. Y., Hou, Q. F., Liu, W. D., Ma, D. S. and Liao, G. Z. (2012). Recent progress and effects analysis of ASP flooding field tests, paper SPE 151285 presented at the SPE Improved Oil Recovery Symposium, 14-18 April, Tulsa, Oklahoma.

51. Chen, M., Raghuraman, B., Bryant, I. and Supp, M., (2006). Streaming potential applications in oil fields, SPE Annual Technical Conference and Exhibition, an Antonio, Texas, USA.

52. Anuar, S. M. M., Jaafar, M. Z. and Sulaiman, W. R. W. (2013). Monitoring Water Alternate Gas (WAG) Process Using Streaming Potential Measurement, Paper SPE 165300 proceedings of the SPE Enhanced Oil Recovery Conference held in Kuala Lumpur, Malaysia, 2-4 July 2013.

53. Omar, S., Jaafar, M. Z., Ismail, A. R., \& Sulaiman, W. R. W. (2013). Monitoring Foam Stability in Foam Assisted Water Alternate Gas (FAWAG) Processes Using Electrokinetic Signals, Paper SPE 165312 proceedings of the SPE Enhanced Oil Recovery Conference held in Kuala Lumpur, Malaysia, 2-4 July 2013.

54. Omar, S., Jaafar, M. Z., Ismail, A. R. and Sulaiman, W. R. W. (2014). Relationship between Foam Stability and The Generated Electrokinetic Signals during FAWAG (Foam Assisted Water Alternate Gas) Process. Journal of Applied Sciences, 14(11): 1123-1130.

55. Anuar, S. M. M., Jaafar, M. Z., Sulaiman, W. R. W. and Ismail, A. R. (2014). Correlation Study between Streaming Potential and Waterfront Progression during Water Alternate Gas (WAG) Injection. Journal of Applied Sciences, 14(17): 1959-1965.

56. Tewari, R. D., Riyadi, S., Kittrell, C., Kadir, F. A., Bakar, M. A., Othman, T. R. T. and Banu, N. (2010). Maximizing Oil Recovery through Immiscible Water Alternating Gas (IWAG) in Mature Offshore Field, SPE-133345-MS. Presented at the SPE Asia Pacific Oil \& Gas Conference and Exhibition held in Brisbane, Queensland, Australia, 18-20 October.

57. Tunio, S. Q. and T. A. Chandio (2012). Recovery enhancement with application of FAWAG for a Malaysian field. J. Applied Sci. Eng. Technol., 4:810

58. Qingfeng, H., Youyi, Z., Yousong, L., and Rui, W. (2012). Studies on Foam Flooding EOR Technique for Daqing Reservoirs After Polymer Flooding. Paper SPE 151955 presented at the 18th SPE Improved Oil Recovery Symposium held in Tulsa, Oklahoma, USA, 14-18 April.

59. Kostoglou, M., Georgiou, M., and Karapantsios, T. D. (2010). A New Device for Accessing Film Stability in Foams: Experiment and Theory. Colloids and Surfaces A: Physicochemical and Engineering Aspects, 382(2011), 64-73.

60. Abdullah, Z. Z., Zain, Z. M., Anua, N. A., and Singhal, A. (2011). Application of Radiactive and Chemical Tracers for Offshore WAG Pilot Project. Paper SPE 143391 presented at the SPE Enhanced Oil Recovery Conference held in Kuala Lumpur, Malaysia, 19-21 July. 